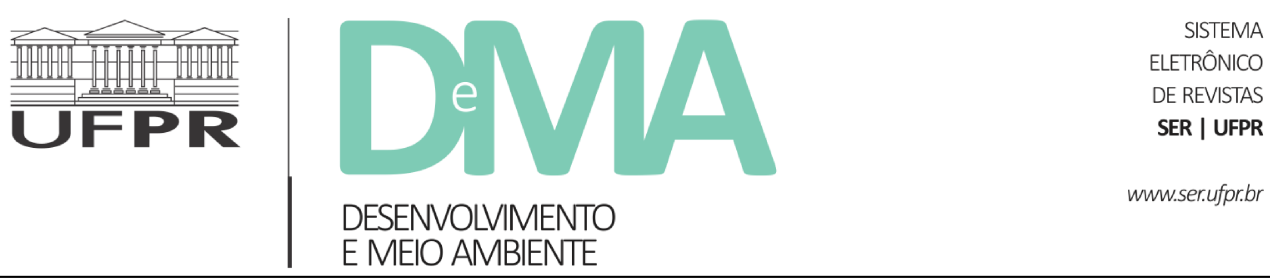

\title{
Conhecimentos, práticas tradicionais e a etnoconservação da natureza
}

\section{Traditional knowledge and practices: an ethnoconservation approach}

\author{
Antonio Carlos DIEGUES ${ }^{1,2 *}$ \\ SP, Brasil. \\ *E-mail de contato: antoniodiegues69@gmail.com
}

${ }^{1}$ Núcleo de Apoio à Pesquisa sobre Populações Humanas e Áreas Úmidas Brasileiras (Nupaub), Universidade de São Paulo (USP), São Paulo,

${ }^{2}$ Programa de Pós-Graduação em Ciência Ambiental (Procam), Universidade de São Paulo (USP), São Paulo, SP, Brasil.

RESUMO: A conservação da biodiversidade no Brasil, tanto terrestre quanto marinha, baseia-se em modelos de parques nacionais e outras modalidades que excluem os povos e comunidades tradicionais que habitam esses espaços. Essa exclusão não é somente física, resultado de pressões para que emigrem, mas também sociocultural, com a proibição de atividades de pequena agricultura, pesca, artesanato e, sobretudo, a negação dos saberes tradicionais sobre a biodiversidade, que o Estado diz proteger. Essa negação é visível quando as comunidades tradicionais moradoras raramente são chamadas para colaborar na elaboração dos "planos de manejo" que definem os diversos espaços de uso e não uso dentro dessas unidades. Essa exclusão faz com que o Estado perca aliados fundamentais para a conservação da biodiversidade. O presente texto procura analisar o papel dos conhecimentos e práticas tradicionais das comunidades moradoras desses territórios nos planos de conservação da biodiversidade, que é fundamental para a conservação democrática e includente de áreas protegidas. Esse modelo é chamado aqui de "etnoconservação".

Palavras-chave: conservação da natureza; etnoconservação; povos e comunidades tradicionais; conhecimentos e práticas tradicionais; manejo tradicional da biodiversidade.

ABSTRACT: Biodiversity conservation in Brazil is based on the imported model of national parks that excludes people, particularly traditional communities from their territories. This exclusion is not only physical, often through forced migration but also sociocultural that includes the whole way of life based on small scale agriculture and fishing, forest gathering and community work. Traditional knowledge on plants., animals, soils is 
also not taken into consideration on conservation areas planning and management. The main consequence of this exclusion is that the State loses support from these communities that should be considered their main allies in biodiversity conservation. This paper aims at analyzing the role of traditional knowledge and practices within a new model of biodiversity conservation that would be more democratic, socially inclusive and more adapted to developing countries situations. This model is called here ethnoconservation.

Keyword: nature conservation; ethnoconservation; peoples and traditional communities; traditional knowledge

\section{Introdução}

A conservação da natureza coloca, hoje, grandes desafios aos conservacionistas, às universidades de pesquisa e aos povos e comunidades tradicionais. A conservação praticada no Brasil, em grande parte dirigida à gestão de áreas de proteção integral, é, na maioria das vezes, dominada por práticas pouco democráticas e participativas, distante das paisagens locais, das necessidades e dos saberes das populações, sobretudo as tradicionais, além de ser pouco inovadora em práticas científicas adaptadas aos ambientes tropicais. Nesse sentido, as instituições de pesquisa e de gestão desses ambientes defrontam-se com o grande desafio de fazer uma análise crítica dos modelos de conhecimento e gestão ainda hoje utilizados e propor novas alternativas de conservação que sejam mais democráticas e participativas, que beneficiem a conservação da biodiversidade e da diversidade cultural, mais interdisciplinares e intensivas em ciência e conhecimentos tradicionais. Esse novo modelo em construção, aqui denominado de etnoconservação pode resultar numa proteção mais eficaz dos habitats e numa melhoria de vida dos povos e comunidades tradicionais que vivem na floresta, na zona costeira, às margens de rios e lagos brasileiros (Diegues, 2000; Marques, 2001).

O ponto de partida para experiências de outros modelos de conservação no Brasil foi dado não por instituições governamentais ou universitárias, mas pelos movimentos sociais, em particular, dos povos indígenas, dos seringueiros amazônicos, dos pescadores artesanais e outros povos tradicionais, propondo alternativas práticas à conservação excludente, tais como as reservas extrativistas florestais e marinhas, as reservas de desenvolvimento sustentável, as experiências de manejo sustentável nos lagos da Amazônia, entre outras. Essas práticas podem e devem combinar unidades de proteção integral como parques nacionais em áreas desabitadas, com unidades de proteção de uso sustentável, formando mosaicos que possam ser apropriados ecológica, cultural e socialmente pelas populações tradicionais. Essa estratégia é distinta dos "corredores biológicos", que, apesar do que dizem seus idealizadores, destinam-se, quase que exclusivamente, à proteção da fauna e da flora.

A própria Reserva de Ecológico-Cultural apresentada pelo Nupaub/USP em 1993 e incorporada ao Sistema Nacional de Unidades de Conservação (2000), aprovada com o nome de Reserva de Desenvolvimento Sustentável (RDS), requer áreas de não uso e proteção integral, designadas e protegidas pelas comunidades tradicionais, aumentando assim sua participação na própria proteção integral. Além disso, não se pode esperar que toda a conservação possa ser realizada somente por áreas protegidas e deve ser estendida a espaços territoriais fora delas como já se tenta fazer na própria Amazônia, envolvendo as 
populações caboclas/ribeirinhas (Ribeiro \& Fabre, 2003). Essas iniciativas são verdadeiros laboratórios de onde podem surgir novas práticas de conhecimento e manejo fora das unidades de conservação onde ainda está a maior parte da biodiversidade no mundo.

A ciência aplicada, hoje utilizada para a conservação, vem, em grande parte, de modelos inadaptados à nossa realidade ecológica e social, em escalas que não podem levar em conta a contribuição local, tais como as chamadas ecorregiões, áreas críticas (hot spots), enfoques ecossistêmicos e os ditames da biologia da conservação. Esses modelos chamados de "grande escala", construídos e divulgados, sobretudo, pelas ONGs multinacionais da conservação (1986), que exercem uma influência desmesurada nas políticas ambientais brasileiras, respondem mais às demandas das instituições bi/multilaterais (Gef, Banco Mundial) e corporativas do que às demandas reais da conservação, que de uma ou outra forma se faz localmente. O resultado dessas práticas tem resultado, muito frequentemente, em conservação insuficiente da nossa fauna e flora e num número elevado de "refugiados da conservação", obrigados a abandonar seus territórios tradicionais em virtude das restrições que sofrem em seu modo de vida (Diegues, 2008).

Isso quer dizer que os modelos novos, como a etnoconservação, devem ser densos em novos conhecimentos científicos, tanto das ciências naturais quanto sociais e saberes tradicionais, e aí reside o grande desafio para as nossas instituições de pesquisa. Por outro lado, apesar da importância que a ciência (e os cientistas) tem na conservação, algumas práticas hoje recomendadas por vários organismos internacionais têm mais a ver com valores éticos e a precaução que com a própria ciência. Esta encontra dificuldades na aplicação de modelos num mundo de incertezas crescentes, em que as mudanças ambientais e sociopolíticas são tão rápidas. Daí a recomendação da adoção de práticas como o manejo adaptativo e a pesca responsável, que insistem, corretamente, em práticas ambientalmente mais respeitosas quando não se tem dados científicos suficientes sobre o comportamento das espécies da flora e fauna e das mudanças a que estão sujeitas pela ação humana (o que é o caso na maioria dos países do Terceiro Mundo, mas não só neles). Essas recomendações somente podem ser postas em prática quando os povos e comunidades tradicionais usuários dos bens da natureza estiverem efetivamente envolvidos tanto no manejo adaptativo quanto na pesca responsável.

\section{Rever conceitos e práticas conservacionistas: sociodiversidade e conhecimento tradicional}

A biodiversidade tornou-se um tema de interesse internacional, sendo, principalmente, objeto de estudo dos cientistas naturais, mas que começa a ganhar espaço também nas ciências sociais, nas quais conceitos como os de povos e comunidades tradicionais, socioantropologia da conservação, etnociência, florestas culturais, sociobiodiversidade, conhecimento e manejo tradicional, território tradicional e formas de apropriação social estão ainda sendo desenvolvidos e disseminados.

Por povos e comunidades entende-se, segundo o Decreto 6.040, que institui a Política Nacional de Desenvolvimento Sustentável dos Povos e Comunidades tradicionais, de 7 de fevereiro de 2007:

$[\ldots]$ grupos culturalmente diferenciados e
que se reconhecem como tais, que possuem
formas próprias de organização social,
que ocupam e usam territórios e recursos 
naturais como condição para sua reprodução cultural, social, religiosa, ancestral e econômica, utilizando conhecimentos, inovações e práticas, gerados e transmitidos pela tradição.

Por outro lado, conhecimento tradicional pode ser definido como o saber e o saber-fazer, a respeito do mundo natural, sobrenatural, produzidos pelos povos e comunidades tradicionais, transmitidos oralmente de geração em geração. Para muitas dessas sociedades, sobretudo as indígenas, existe uma interligação orgânica entre o mundo natural, o sobrenatural e a organização social. Nesse sentido, para estes dois últimos termos, não existe uma classificação dualista, uma linha divisória rígida entre o "natural" e o "social", mas sim um continuum entre ambos. Assim, Descola (1997) sugere que para os achuar da Amazônia, a floresta e as roças, longe de se reduzirem a um lugar de onde se retiram os meios de subsistência, constituem o palco de sociabilidades diversas em que convivem seres humanos, seres sobrenaturais e os animais e plantas. Para muitos povos indígenas, os humanos podem se tornar animais e estes converterem-se em humanos. Nesse sentido, ainda segundo Descola, as cosmologias indígenas amazônicas não fazem distinções ontológicas entre humanos, de um lado, e um grande número de animais e seres sobrenaturais, de outro. $O$ autor enfatiza a ideia de interligação entre essas espécies, ligadas umas às outras por um vasto continuum, governada pelo princípio da sociabilidade, no qual a identidade dos humanos, vivos ou mortos, das plantas, dos animais e dos espíritos é completamente relacional e, portanto, sujeita a mutações.

É, portanto, essencial ter-se em conta que conceitos como os de "natureza selvagem", "ecossistema", "ecorregiões", promovidos pelas ONGs multinacionais da conservação, pertencem à ciência ocidental e são símbolos claros da separação entre cultura e natureza e que, por isso, não fazem sentido nas cosmologias dos povos e comunidades tradicionais.

Lévi-Strauss, em $O$ Pensamento Selvagem, enfatiza a atitude e espírito científico dos povos indígenas ao afirmar que, para elaborar técnicas muitas vezes complexas, que permitem cultivar sem terra ou sem água, transformar grãos ou raízes tóxicas em alimentos, há uma atitude científica, uma curiosidade assídua e alerta, uma vontade de conhecer pelo prazer de conhecer, pois apenas uma fração das observações e experiências podia fornecer resultados práticos e imediatamente utilizáveis (1976). Lévi-Strauss afirma, portanto, que existem dois modos diferentes de pensamento científico, não em função de estágios desiguais de desenvolvimento do espírito humano, mas dois níveis estratégicos em que a natureza se deixa abordar pelo conhecimento científico: um aproximadamente ajustado ao da percepção e ao da imaginação e outro deslocado, como se as relações necessárias, objeto de toda ciência, pudessem ser atingidas por dois caminhos diferentes, sendo um próximo da intuição sensível e o outro mais deslocado (1989, p. 30). Michael Balick \& Paul Cox (1996) têm posição semelhante ao afirmar que o conhecimento tradicional indígena e o científico ocidental partem dos mesmos princípios epistemológicos.

William Balée, em Fooprints of the Forest (1993), enfatiza também uma outra diferença relevante entre o pensamento científico moderno e o tradicional. Enquanto o primeiro é comunicado a partir da escrita, o segundo utiliza a oralidade. Nesse sentido, o conhecimento tradicional somente pode ser interpretado dentro do contexto da cultura em que ele é gerado. Para Balée, é a escrita e os mecanismos a ela associados que explicam por que a botânica lineense permite a identificação de mais de 30.000 espécies 
de plantas na Amazônia, enquanto que dificilmente um grupo indígena emprega mais de 1.000 nomes diferentes para essa flora.

Em um extenso levantamento bibliográfico (aproximadamente 900 trabalhos selecionados) realizado pelo Nupaub (Diegues \& Arruda, 2001), constatou-se que, até final da década de 80 , a maioria dos trabalhos $(44,2 \%)$ versava sobre povos indígenas e eram realizados predominantemente por etnólogos/ antropólogos. Já a partir do início da década de 90, a situação se inverte: a maioria dos trabalhos $(59,2 \%)$ é sobre comunidades tradicionais não indígenas dentro das diversas disciplinas ligadas às etnociências, com destaque àqueles sobre quilombolas, ribeirinhos amazônicos, pantaneiros, pescadores artesanais e caiçaras. Segundo Diegues \& Arruda (2001), cerca de $61 \%$ das publicações sobre povos indígenas e comunidades tradicionais usam as técnicas da etnociência e $25 \%$ do total descrevem técnicas de manejo da biodiversidade usando o conhecimento tradicional. Além disso, passa-se do montante de 273 trabalhos de pesquisa realizados até a década de 1980 a 416 na década de 1990.

\section{A biodiversidade vista pela ciência e aquela produzida pelos povos tradicionais $e$ comunidades tradicionais}

A partir do exposto acima, fica evidente que existem diferenças entre as formas pelas quais as populações tradicionais produzem e expressam seu conhecimento sobre o mundo natural e aquelas que foram desenvolvidas pela ciência moderna. Essas diferentes visões refletem-se no uso de conceitos desenvolvidos e aceitos por esta última, como o de recursos naturais, biodiversidade e manejo.
Para a ciência moderna, a biodiversidade pode ser definida como a "variabilidade entre seres vivos de todas as origens, inter alia, a terrestre, a marinha e outros ecossistemas aquáticos e os complexos ecológicos dos quais fazem parte: isso inclui a diversidade no interior das espécies, entre as espécies e entre espécies e ecossistemas" (artigo 2 da Convenção da Biodiversidade-CBD). Na concepção clássica, a biodiversidade é uma característica do mundo chamado natural, produzida exclusivamente por este e analisada segundo as categorias classificatórias propostas pelas ciências ou disciplinas científicas, como a botânica, genética, a biologia etc.

Os povos e comunidades tradicionais não só convivem com a biodiversidade, mas nomeiam e classificam as espécies vivas segundo suas próprias categorias e nomes. Uma importante diferença, no entanto, é que essa natureza diversa não é vista como selvagem em sua totalidade; ela foi e é domesticada, manipulada. Uma outra diferença é que essa diversidade da vida não é vista como "recurso natural", mas sim como um conjunto de seres vivos que tem um valor de uso e um valor simbólico, integrado numa complexa cosmologia.

Nesse sentido, pode-se falar numa etnobiodiversidade, isto é, a riqueza da natureza da qual participam os humanos, nomeando-a, classificando-a, domesticando-a, mas de nenhuma maneira selvagem e intocada.

Pode-se concluir que a biodiversidade pertence tanto ao domínio do natural quanto do cultural, mas é a cultura enquanto conhecimento que permite às populações tradicionais entendê-la, representá-la mentalmente, manuseá-la, além de retirar espécies, colocar outras e enriquecendo assim a própria sociobiodiversidade ou etnobiodiversidade. 
Nesse sentido os seres vivos, em sua diversidade, participam, de uma ou outra forma, do espaço domesticado ou pelo menos identificado, seja como domesticado, seja como não domesticado, mas conhecido. Eles pertencem a um lugar, um território enquanto lócus em que se produzem as relações sociais e simbólicas.

A biodiversidade usualmente definida pelos cientistas é fruto exclusivo da natureza, não pertence a lugar nenhum senão a uma teórica teia de inter-relações e funções, como pretende a teoria dos ecossistemas. No fundo, o conhecimento da biodiversidade tido como exclusivo da ciência, e aí reside um dos graves problemas no mundo moderno em que parcela importante das descobertas científicas é feita em laboratórios de empresas multinacionais. Para que esse conhecimento se produza sem interferência dos outros homens, o cientista necessita, usualmente, de um não lugar, um parque nacional ou uma outra área de proteção que não permite a presença humana, incluindo a presença daquelas populações tradicionais que colaboraram para que aquele pedaço de seu território se mantivesse preservado. $\mathrm{O}$ parque nacional acaba representando um hipotético mundo natural primitivo, intocado, mesmo que grande parte dele já tenha sido manipulada por populações tradicionais durante gerações, criando paisagens mistas de florestas já transformadas e outras que raramente são visitadas para as operações de caça, coleta etc. Esses espaços florestados assim constituídos são paisagens, em grande parte resultante da ação humana. Uma política conservacionista equivocada que transforma esses lugares em não lugares, com a expulsão das populações tradicionais pode estar abrindo espaço para que esses não lugares se tornem o domínio de pesquisa das multinacionais ou de convênios entre entidades de pesquisa nacionais e internacionais, criados como reservas futuras para mineração, hidroelétricas e ao final, "privatizados", como manda o manual neoliberal hoje vigente no Brasil. Talvez seja por isso que as grandes entidades conservacionistas internacionais e governos associem de forma tão íntima a conservação da biodiversidade e as áreas protegidas vazias de seus habitantes tradicionais e de sua cultura.

Apesar dos avanços internacionais no reconhecimento da importância dos conhecimentos tradicionais como é feito em vários artigos da $\mathrm{CDB}$, em particular no artigo $8 \mathrm{j}$, que trata da repartição dos benefícios decorrentes do uso desses saberes por empresas, ainda existe, para alguns, a dúvida se uma comunidade analfabeta e socialmente marginalizada, como os pescadores artesanais, possa ter um conjunto de práticas e saberes úteis para a conservação. No entanto, o estudo clássico do antropólogo John Cordell entre os pescadores artesanais do sul da Bahia é um exemplo de como comunidades pobres e marginalizadas conseguiram sistemas de apropriação dos recursos pesqueiros baseados no conhecimento e práticas tradicionais complexas (Cordell, 1983).

Muitas das instituições governamentais do meio ambiente são controladas por cientistas naturais que consideram ser o conhecimento científico ocidental como a única base para o estabelecimento de manejo costeiro. A partir desse pressuposto equivocado, eles impõem sistemas de manejo frequentemente baseados em dados biológicos incompletos, trazendo consequências negativas para a pesca. Instala-se então um confronto entre os saberes, o científico moderno e o tradicional, ao invés de uma colaboração frutí-fera. Na base desse conflito está, sem dúvida, a questão do poder associado ao conhecimento científico, sendo este último utilizado pelo governo para justificar muitas de suas intervenções em áreas social e ambientalmente frágeis. 
Reconhecer a importância do conhecimento científico na gestão dos recursos naturais teria que partir da aceitação governamental de que os portadores desse conhecimento, as comunidades tradicionais, têm o direito de permanecer em seu território e continuar exercendo seu modo tradicional de vida. Isso é negado a essas comunidades no caso em que seus territórios são transformados em unidades de proteção integral ou ocupados por grandes projetos, como portos, hidroelétricas, áreas de mineração, entre outros.

Como afirma Ruddle (2000):

O conhecimento local pode ser entendido como um sistema de poder e portanto pode fornecer autoridade às comunidades para exercer seu sistema tradicional de manejo. Isso é particularmente importante em países tropicais onde o conhecimento científico é ainda insuficiente (p. 291).

Ainda que a ciência moderna e a tradicional sejam duas formas de saberes, a relação entre ambas continua sendo pouco estudada. Como afirmam Gadgil et al. (1993):

[...] o conhecimento tradicional, com seu enfoque diacrônico, ao contrário da ciência moderna com sua análise sincrônica, tem uma importância grande para a conservação. Mas como o conhecimento tradicional está intimamente ligado à prática e às crenças, é mais difícil de se explicar esse saber no âmbito da ciência ocidental (p. 155).

Essa situação está mudando vagarosamente no Brasil e está havendo um aumento do interesse pelo conhecimento tradicional e pela etnociência dentro e fora das universidades e institutos de pesquisa.

Apesar das ameaças que pairam sobre os sistemas tradicionais de apropriação dos espaços tradicio- nais, o conhecimento de que dispõem as comunidades tradicionais sobre seu território constitui um elemento importante a ser incorporado em novas experiências de gestão dos recursos e espaços. Esses conhecimentos e sistemas, no entanto, não podem ser transferidos mecanicamente aos sistemas atuais de gestão desses recursos. É importante se afirmar que a gestão de recursos naturais é, basicamente, a regulamentação do comportamento humano no uso dos recursos e não a regulamentação dos recursos naturais enquanto tais. A gestão tradicional inclui um número maior de objetivos, além dos econômicos e da eficiência técnica, englobando a qualidade de vida, a sociabilidade e os aspectos simbólicos. No caso da pesca artesanal, a transferência de mecanismos de controle pesqueiros de países desenvolvidos, como o de quotas de pesca transferíveis, sem um conhecimento adequado da racionalidade subjacente às atividades pesqueiras tradicionais, pode levar a uma grande desorganização da própria atividade pesqueira.

\subsection{Manejo científico e o etnomanejo}

O conceito de manejo das ciências naturais também é distinto do etnomanejo, do manejo realizado pelas tradições tradicionais. A definição apresentada do manejo científico, dos ecossistemas que se encontra no Glossário de Ecologia, da Aciesp (1987), é sintomática nesse sentido:

Aplicação de programas de utilização dos ecossistemas, naturais ou artificiais, baseada em teorias ecológicas sólidas, de modo que mantenha, da melhor forma possível as comunidades vegetais e/ou animais como fontes úteis de produtos biológicos para o homem, e também como fontes de conhecimento científico e de lazer. A 
orientação de tais programas deve garantir que os valores intrínsecos das áreas naturais não fiquem alterados, para o desfrute das gerações futuras.

Fica claro nessa definição que existe somente o manejo chamado "científico", dentro dos parâmetros da ciência cartesiana e reducionista, baseada em "teorias ecológicas sólidas". Seria importante que se definisse o que são teorias ecológicas sólidas num domínio científico em que as teorias da conservação mudam rapidamente. Veja-se, por exemplo, a teoria dos refúgios, que serviu de base, na década de 7080, para o estabelecimento de parques nacionais na Amazônia, que se transformaram, eles mesmos, em verdadeiras ilhas de conservação e que depois passou ao desuso. Hoje se fala em corredor ecológico como forma de se resolver a fragmentação da mata e a insularização das unidades de conservação, esta resultante, em parte, da aplicação da teoria dos refúgios. Os programas de "corredores ecológicos", um dos financeiramente mais bem dotados do Brasil e aplicados em outras partes do mundo pelas mesmas ONGs conservacionistas internacionais antes mencionadas, não têm sido devidamente avaliados pela sociedade brasileira em sua complexidade ecológica, mas sobretudo social e política (Diegues, 1996).

Para esse manejo científico, exige-se, por exemplo, o "conhecimento profundo do ecossistema", mesmo quando se sabe que as informações científicas necessárias não são facilmente disponíveis e que os limites dos ecossistemas variam segundo a formação de cada cientista, seja ele biólogo, pedólogo, botânico etc.

Para a etnociência, o manejo é realizado também pelas populações tradicionais indígenas e não indígenas. Para Balée (1993), esse manejo implica na manipulação de componentes inorgânicos ou orgânicos do meio ambiente, que traz uma diversidade ambiental líquida maior que a existente nas chamadas condições naturais primitivas, em que não existe presença humana.

Para esse autor, a questão transcende a distinção habitual entre preservação e degradação, na medida em que, ao contrário da preservação, o manejo implica em interferência humana. Num ecossistema manejado, algumas espécies podem se extinguir como resultado dessa ação, ainda que o efeito total dessa interferência possa resultar num aumento real da diversidade ecológica e biológica de um lugar específico ou região. Balée mostrou como, no caso dos ka'apor, existe um manejo tradicional indígena que resulta num aumento de espécies de determinados habitats, ainda que esse resultado não tenha sido buscado intencionalmente. Esse autor, assim como outros (Gomez-Pompa, 1992), indica que os povos indígenas não só têm um conhecimento aprofundado dos diversos habitats e solos em que ocorrem as espécies, como também os classificam com nomes distintos. Eles também manipulam esses ambientes e sua flora e fauna, por meio, inclusive, de práticas agrícolas, como a do pousio, que acabam resultando numa maior diversidade de espécies nesses habitats manipulados do que nas florestas consideradas nativas.

Finalmente, é importante se afirmar que essa sociobiodiversidade é, em grande parte, resultado dos conhecimentos e práticas realizados nos territórios onde os grupos tradicionais produzem também seu modo de vida.

\section{Novos critérios para seleção de áreas críticas para a conservação}

Finalmente, um outro aspecto que mostra a divergência dos enfoques sobre as estratégias de 
conservação da biodiversidade por parte das grandes ONGs internacionais (Diegues, 1996) diz respeito aos critérios usualmente utilizados para se definir "hot spots" (áreas críticas) prioritários para a conservação: esses critérios são quase que totalmente de ordem biológica. Dentro de possíveis novos parâmetros de uma etnoconservação poder-se-ia pensar em critérios decorrentes das paisagens criadas pelas populações tradicionais, como foram descritas anteriormente. Um dos critérios a ser incorporado é o da existência de áreas de alta biodiversidade decorrente do conhecimento e do uso tradicional realizado pelos povos tradicionais indígenas e não indígenas. Essas populações tradicionais, ao invés de serem expulsas de suas terras para a criação de um parque nacional, passariam a serem valorizadas e recompensadas pelo seu conhecimento e práticas de uso do território que deram origem a esses mosaicos de paisagens que incluem um gradiente de florestas pouco ou nada tocadas por elas até aquelas manejadas. Ter-se-ia, sem dúvida, mapas de áreas críticas para a diversidade, diferentes daqueles gerados em workshops financiados por instituições ambientalistas internacionais. Evidentemente, esses mapas somente poderiam ser realizados com a utilização de indicadores de biodiversidade que não são somente de ordem biológica, mas provenientes de uma nova etnociência da conservação. No entanto, o que ocorre é que nos workshops promovidos, em grande parte, por grandes ONGs internacionais da conservação (2008), somente são usados critérios biológicos, cabendo às ciências sociais indicar somente "as ameaças antrópicas" à conservação, incluindo aí, muitas vezes, a própria presença das populações tradicionais. Quando, nesses workshops, isso é criticado pelos raros cientistas sociais convidados, a resposta é que o modelo não comporta esses dados socioculturais. É necessário se desenvolver metodologias por meio das quais as áreas críticas de conservação sejam selecionadas porque nelas existem práticas tradicionais que, de uma forma ou de outra, são igualmente responsáveis pelo estado de conservação da área. A partir daí teríamos outros "mapas de áreas críticas da conservação", que exigem outras práticas conservacionistas mais eficientes e democráticas.

Essa nova alternativa poderia ser realizada por inventários da etnobiodiversidade realmente participativos, com plena anuência e cooperação das populações tradicionais, manejadoras da biodiversidade.

\section{A apropriação social e simbólica do território tradicional}

O território pode ser definido "como os espaços necessários a reprodução cultural, social e econômica dos povos e comunidades tradicionais, sejam eles utilizados de forma permanente ou temporária" (Decreto 6.040 que institui a Política Nacional de Desenvolvimento Sustentável dos Povos e Comunidades tradicionais, de 7 de fevereiro de 2007).

A posse social do território dos povos e comunidades tradicionais implica não somente em relações com a natureza (florestas, mares) e com a sociedade, mas também em conexões simbólicas com o mundo não material. Conceitos e representações do mundo natural e seus recursos são distintos em sociedades tradicionais e sociedades urbano-industriais. Godelier (1984) argumenta que essas duas sociedades apresentam racionalidades distintas e cada uma delas dispõe de um conjunto de regulamentos elaborados e utilizados para atingir seus objetivos. De acordo com esse antropólogo, cada sistema social e econômico cria um modo específico de uso dos recursos naturais e do trabalho e, consequentemente, cria normas para o 
bom e mau uso dos recursos naturais. De acordo com Godelier (1984), no interior das relações materiais com a natureza existe um aspecto não material que unifica as três funções do conhecimento: representar, organizar e legitimar as relações sociais e com a natureza. Para se entender o processo material de produção é essencial, portanto, levar-se em conta os mitos e símbolos usados tanto pelas comunidades que vivem da mata quanto do mar para representar esses ambientes e os seres que aí vivem. O processo de produção tradicional incorpora elementos simbólicos que atuam não sobre a natureza em si, mas sobre as forças sobrenaturais que garantem uma colheita abundante ou pesca proveitosa e, por vezes, castigam aqueles que são demasiadamente ambiciosos. Os territórios, tanto marítimos quanto florestais, além de comportarem áreas de uso comum, trabalhados pela ação coletiva, exibem marcas (pedras submersas, certas árvores, terras em pousio, cemitérios, capelas) que demonstram a antiguidade da ocupação e que são reconhecidas por todos os moradores como sinais de uso ancestral e pilares da memória coletiva.

No Brasil, a questão dos territórios tradicionais e a apropriação social de seus recursos somente há pouco tempo vêm recebendo atenção por parte dos pesquisadores. Uma das razões é que muitos deles são tratados como espaços vazios ainda que sejam habitados por comunidades tradicionais, socialmente invisíveis até recentemente. Somente há pouco tempo esses grupos sociais tornaram-se socialmente mais visíveis, quando começaram a se organizar e resistir às expulsões de seus territórios. É o caso dos se-ringueiros, quebradeiras de coco-babaçu, pescadores artesanais, entre outros, que se or-ganizaram como associações e movimentos, tais como o Conselho Nacional dos Seringueiros, o Movimento de Pescadores e pescadoras (MPP), diversos fóruns, tais como o fórum de comunidades tradicionais do litoral norte de São Paulo e sul-fluminense e o fórum de comunidades tradicionais do Vale do Ribeira, em São Paulo, que reúnem povos indígenas, comunidades quilombolas e caiçaras. A nível federal estão representados na Comissão Nacional de Povos e Comunidades Tradicionais, criada em 2006 e hoje transformada em um Conselho Nacional de Povos e Comunidades Tradicionais, respon-sáveis principalmente pela aplicação da Política Nacional de Desenvolvimento Sustentável dos Povos e Comunidades Tradicionais (2007).

A maioria desses movimentos hoje se concentra na luta pelo controle de seu território ou parte dele contra as ameaças de expropriação a que estão sujeitos, à sua cultura, ao seu modo de vida tradicional, contando com o apoio jurídico do Ministério Público Federal e da Defensoria Pública, de ONGs socioambientais, de institutos de pesquisa e ensino.

$\mathrm{O}$ estabelecimento de áreas protegidas sobre territórios pertencentes a comunidades litorâneas também afetou negativamente o modo de vida dos pescadores artesanais. Muitas dessas áreas nas regiões costeiras eram e são habitadas por pescadores artesanais que desenvolveram formas específicas de apropriação dos recursos do mar. Frequentemente, as matas associadas aos ecossistemas litorâneos conservaram-se em bom estado não porque foram transformadas em parques nacionais, mas sobretudo porque eram habitadas por essas comunidades tradicionais. Ainda assim, a legislação brasileira pressupõe a expulsão desses pescadores artesanais de seus territórios ancestrais. 


\section{Conclusões}

O que se propõe para a criação de uma nova ciência da conservação é uma síntese entre o conhecimento científico e o tradicional. Para tanto, é preciso, antes de tudo, reconhecer-se a existência dos territórios das comunidades tradicionais, de seus conhecimentos e práticas como formas igualmente válidas de se representar e manejar a sociobiodiversidade.

Romper com os padrões clássicos dessa ciência reducionista não é tarefa fácil, pois nossas próprias instituições de pesquisa e ensino são, em geral, unidisciplinares, discriminadoras dos saberes tradicionais, marcadas por "correias de transmissão" que nos ligam aos grandes centros, dentro e fora do país, onde são gerados modelos científicos reducionistas que, transformados em práticas (ou ideologias), levam a uma conservação hegemônica, autoritária e pouco eficaz.

A superação desses modelos e práticas constitui, a meu ver, o grande desafio que se coloca às instituições brasileiras de pesquisa, de ensino, às ONGs, órgãos ambientais e organizações dos povos tradicionais. A construção social de um modelo que chamamos de etnoconservacionista poderá resultar numa conservação ambientalmente mais eficaz e numa melhoria das condições sociais e econômicas, sobretudo para os povos e comunidades tradicionais que vivem diretamente dos benefícios da biodiversidade que ajudam a manter.

\section{Referências}

ACIESP - Academia de Ciências do Estado de São Paulo. Glossário de Ecologia, São Paulo, 1987.

Balée, W. Footprints of the Forest: Ka'apor ethnobotany - the historical ecology of plant utilization by an Amazonian People.
New York: Columbia Univ. Press, 1993.

Balick, M.; Cox, P. Plants, people and culture: the science of ethnobotany. New York: Scientific American Library, 1996.

Cordell, J. C. Locally managed sea territories in Brazilian coastal fishing. Paper prepared for FAO Conference on Coastal Lagoon Fisheries. Rome, 1983.

Descolla, P. Ecologia e Cosmologia. In: Castro, E.; Pinton, F. Faces do Trópico Úmido. Belém: Edit. Cejup, 1997.

Diegues, A. C. O mito moderno da natureza intocada. Hucitec, 1996.

Diegues, A. C. (Org.). Etnoconservação: novos rumos para a proteção da natureza nos trópicos. $2^{\mathrm{a}}$.ed. São Paulo: Annablume, Nupaub/USP e Hucitec, 2000.

Diegues, A. C.; Arruda, R. S. V. Saberes tradicionais e Biodiversidade. MMA, Brasília, 2001.

Diegues, A. C. (Org.). A ecologia politica das grandes ONGS transnacionais conservacionistas. Nupaub/USP, São Paulo, 2008.

Gadgil, M.; Berkes, F.; Folke, C. Indigenous knowledge for biodiversity conservation. Ambio, 22(2-3), 1993.

Godelier, M. L'idéel et le materiel. Fayard, Paris, 1984.

Gomez-Pompa, A.; Kaus, A. Taming the wilderness myth. Bioscience, 42(4), 271-279, 1992.

Levi-Strauss, C. O pensamento selvagem. Campinas: Papyrus. Edit., 1989.

Marques, J. G. Pescando Pescadores. $2^{\mathrm{a}}$.ed. Nupaub/USP, São Paulo, 2001.

Ribeiro, M.; Fabré, N. Sistemas abertos sustentáveis-SAS, uma alternativa de gestão ambiental na Amazônia, Manaus: Edua, 2003

Ruddle, K. Systems of knowledge: dialogue, relationships and process. In: Begossi, A.; Hens, L. Environment, development and sustainability. Kluwer Academic Publishers, Vol. 2, ns. 3-4, 2000. 